\title{
EL TRIBUNAL DE JUSTICIA DE LA UNIÓN EUROPEA COMO ACTOR DE CONSTITUCIONALIDAD: SOBRE LA INTERPRETACIÓN DEL DERECHO A LA NO DISCRIMINACIÓN EN EL TRABAJO Y SUS CONSECUENCIAS ${ }^{1}$
}

\author{
María José Carazo Liébana \\ doi: http://dx.doi.org/10.18543/ed-65(1)-2017pp45-71
}

\begin{abstract}
Sumario: 1. Cuestiones Previas. 2. ¿Desigualdad De trabajadoRES POR INDEMNIZACIÓN DIFERENTE DEPENDIENDO DE LA TEMPORALIDAD DEL CONTRATO? LA RECEPCION DELA JURISPRUDENCIA DEL TRIBUNAL DE JUSTICIA DE LA UNION EUROPEA POR LOS ÓRGANOS JUDICIALES. 2.1. Aplicación por los Tribunales nacionales de la jurisprudencia comunitaria en relación a los trabajadores interinos. a) Ámbito de aplicación de la cláusula 4, apartado 1, del Convenio Marco ¿Se incluye entre las condiciones de trabajo el derecho a la indemnización por finalización de la relación laboral? b) ¿Existen razones objetivas para justificar un tratamiento diferenciado en relación a la indemnización, teniendo en cuenta el carácter temporal o no de la relación de trabajo? c) ¿Es discriminatoria la regulación del Estatuto de los Trabajadores? 2.2. Aplicación por los Tribunales nacionales de la jurisprudencia comunitaria en el trato igualitario entre trabajadores temporales $y$ fijos. 3. LA RECEPCIÓN DE LA JURISPRUDENCIA DEL TJUE POR EL TRIBUNAL CONSTITUCIONAL. 4. HACIA LA CONSOLIDACIÓN DEL TJUE COMO ACTOR DE CONSTITUCIONALIDAD.
\end{abstract}

${ }^{1}$ Este trabajo ha sido realizado en el marco del Proyecto $+\mathrm{D}+\mathrm{i}$ del Plan Nacional: Las entidades locales, sus relaciones y competencias. Realidad, efectos y consecuencias de la racionalización y sostenibilidad financiera en clave nacional y europea (DER201674843-C3-1-R), investigadora principal Dra. D. ${ }^{a}$ Eloisa Carbonell Porras. 


\section{CUESTIONES PREVIAS}

Hace unos meses se celebró en los medios de comunicación la noticia de que el Tribunal Superior de Justicia de Madrid (en adelante TSJM) en su sentencia 613/2016 de 5 de octubre había fallado a favor de una trabajadora del Ministerio de Defensa haciendo una interpretación de la normativa española a resultas de la jurisprudencia comunitaria (especialmente la sentencia del Tribunal de Justicia de la Unión Europea de 14 de septiembre de 2016) en torno a la equiparación, por el principio de igualdad, de los trabajadores. Ello con independencia de que fuesen temporales o, como el caso que nos ocupa, interinos. Efectivamente la noticia fue portada de los medios de comunicación, debatida en las redes sociales y casi se convirtió en trending topic en twiter el día de su publicación ${ }^{2}$. Piénsese que la indemnización por despido de 20 días por año de servicio trabajado para los interinos en España podría costar unos 250 millones de Euros al año. Según el sindicato CSIF la tasa de interinidad es del $11 \%$ y en algunos sectores como Educación, Justicia y Sanidad ese porcentaje se eleva a un $20 \%$.

En consonancia con la misma sentencia del Tribunal de Justicia de la Unión Europea (en adelante TJUE) la Sala de lo Social del Tribunal Superior de Justicia del País Vasco dicta resolución el 18 de octubre del 2016 fijando una indemnización de veinte días a la finalización de un contrato por obra o servicio determinado en una empresa privada que se dedicaba a la prestación de servicios de conserjería, limpieza y mantenimiento. De esta forma, se establece una indemnización al trabajador temporal idéntica a la establecida en la legislación laboral al contratado fijo, aunque el Estatuto de los Trabajadores diga otra cosa, y todo ello de acuerdo con la interpretación que hace el TJUE de la cláusula de igualdad en los contratos de trabajo.

Se trata de un tema de vital importancia desde la perspectiva constitucionalista y más concretamente desde la perspectiva -hoy imprescindible- del constitucionalismo multinivel. En el desarrollo de este trabajo se comenzará con una plasmación de los fallos judiciales fundamentales en el análisis del tema para, posteriormente, hacer una reflexión de lo que nos deparará el futuro en la interpretación de nuestro Ordenamiento jurídico-constitucional y las consecuencias que ello traerá consigo. No se nos escapa que la influencia del derecho comunitario en la interpretación de la Constitución ha sido progresiva, pero hoy en día está encontrando su punto más álgido. Incluso el Tribunal Constitucional (en adelante TC) asume pautas interpretativas del

${ }^{2}$ La abogacía del Estado ha presentado un recurso de casación ante el Tribunal Supremo contra la sentencia del TSJM, este recurso ha paralizado el cobro de la indemnización por parte de la afectada. 
TJUE en contra de lo que ha sido su criterio en sentencias precedentes, como veremos en los casos que se indican a continuación.

Como señalábamos más arriba, el asunto que nos ocupa ha suscitado un debate en la opinión pública con algunas cuestiones que deben ser subrayadas desde un punto de vista constitucionalista (aparte de su gran importancia para los expertos laboralistas). Y así, lejos de analizar si la sentencia del TJUE es más o menos exquisita en su tratamiento, por el uso de la analogía, de la interinidad respecto a los contratos temporales. O lejos de tratar si con este fallo jurisprudencial estamos acercándonos al modelo de contrato único tan traído a la esfera política por algún partido político ${ }^{3}$, conviene analizar lo que supone el acercamiento de posiciones interpretativas de la legislación nacional utilizando como parámetro la normativa supranacional, a fin de evitar contradicciones difíciles de casar cuando, como en nuestro caso, estamos en una dimensión necesariamente supranacional en la interpretación de los derechos y libertades reconocidos en la Constitución.

Pues bien, el análisis no es otro que la posible discriminación en nuestro país de los trabajadores interinos o temporales en relación al resto de los trabajadores, lo que supone una infracción de la normativa comunitaria. Concretamente de la cláusula cuatro del Acuerdo Marco sobre el trabajo de duración determinada del 18 de marzo de 1999 que figura en el Anexo de la Directiva 1999/70/CE del Consejo, de 28 de junio de 1999 y que prevé la no discriminación entre trabajadores fijos y temporales. En aplicación de la Directiva entiende el TJUE que el Real Decreto Legislativo 2/2015, de 23 de octubre, por el que se aprueba el texto refundido de la Ley del Estatuto de los Trabajadores al no contemplar indemnización alguna para los trabajadores interinos es discriminatorio conforme a las normas comunitarias. Igualmente puede entenderse, y así lo hace el TSJ País Vasco, que la fijación de una indemnización inferior por despido por causas objetivas a los trabajadores temporales frente a los fijos puede concebirse como discriminación en las relaciones de trabajo tal como prevé la citada Directiva.

El asunto que da lugar a la sentencia del TJUE trae su causa en una trabajadora del Ministerio de Defensa (Ana de Diego Porras) que encadenó durante siete años y dos meses un contrato de interinidad en sustitución de una trabajadora liberada sindical. La demandada fue despedida sin derecho a indemnización dado que su contrato concluía de forma natural en el momento de la incorporación de la trabajadora sustituida. Tras la reincorporación se comunicó a la demandante la extinción de su contrato de trabajo sin derecho a indemnización alguna de conformidad con el art. 49.1.b) ${ }^{4}$ del Estatuto de

${ }^{3}$ Referencia a «Ciudadanos».

4 Según el cual «El contrato de trabajo se extinguirá:... b) Por las causas consignadas válidamente en el contrato salvo que las mismas constituyan abuso de derecho mani- 
los trabajadores (en adelante ET). Ello frente a la indemnización que corresponde a los contratos temporales (12 días por año de servicio) y los indefinidos (20 días por año de servicio por causas objetivas con un máximo de 12 mensualidades y 33 días por año de servicio con un máximo de 24 mensualidades por despido improcedente). Piénsese en los términos de la interpretación pues si el foco está en la discriminación según la dicotomía temporal / indefinido, entonces también sería abusiva, por atentar contra el principio de igualdad, la diferenciación en la legislación de la indemnización que corresponde al trabajador según sea temporal o indefinido, tal como sentencia el TSJ País Vasco en su resolución de 18 de octubre de 2016. Parece obvio que si se plantea la cuestión de esta forma, como por otra parte es lógico teniendo en cuenta la sentencia del TJUE, debería elevarse la indemnización de los contratos temporales de doce días a veinte días en caso de despido por causas objetivas.

El Juzgado de lo Social n. ${ }^{\circ} 1$ de Madrid desestima el recurso interpuesto por la afectada, si bien reconoce que los contratos se celebraron en fraude de ley y que su relación laboral debía de haberse considerado indefinida. La sentencia fue recurrida ante el TSJ Madrid que planteó una serie de cuestiones prejudiciales al TJUE que fueron resueltas en sentencia del 14 de septiembre de 2016 (C-596/14). Razones que hace suya el primero para fallar a favor de la trabajadora en su derecho a recibir una indemnización, asimilando la situación de los trabajadores interinos al resto de los trabajadores. Se entiende así discriminatoria la normativa española al diferenciar sin razón objetiva a unos trabajadores y otros. Dice textualmente «El mero hecho de que este

fiesto por parte del empresario. c)... A la finalización del contrato, excepto en los casos del contrato de interinidad y de los contratos formativos, el trabajador tendrá derecho a recibir una indemnización de cuantía equivalente a la parte proporcional de la cantidad que resultaría de abonar doce días de salario por cada año» En la Disposición Transitoria Decimotercera del Estatuto de los Trabajadores, y tal y como quedó previsto en el Real Decreto 10/2010 de 16 de junio (Reforma Laboral de 2010), se especifica que la indemnización por finalización de contrato temporal, establecida en el artículo 49.1.c) del Estatuto de los Trabajadores se aplica de modo gradual:

- Ocho días de salario por cada año de servicio para los contratos temporales celebrados hasta el 31 de diciembre de 2011.

- Nueve días de salario por cada año de servicio para los contratos temporales celebrados a partir del 1 de enero de 2012.

- Diez días de salario por cada año de servicio para los contratos temporales celebrados a partir del 1 de enero de 2013.

- Once días de salario por cada año de servicio para los contratos temporales celebrados a partir del 1 de enero de 2014.

- Doce días de salario por cada año de servicio para los contratos temporales que celebrados a partir del 1 de enero de 2015. 
trabajador haya prestado sus servicios en virtud a un contrato de interinidad no puede constituir una razón objetiva que permita justificar la negativa a que dicho trabajador tenga derecho a la mencionada indemnización»" $\mathrm{A}$ sensu contrario, la diferenciación podría ser posible si está fundamentada en causas objetivas (no considerándose como tales el carácter temporal o indefinido de la relación laboral). Sí habría causas objetivas cuando se tratara de trabajadores con funciones diferentes o con requisitos formativos también diferentes. El TSJ de Madrid concluye fijando la indemnización de la trabajadora de conformidad con la respuesta del TJUE en $6.141,85 €$ y señalando que "tiene derecho a igual indemnización que la que correspondería a un trabajador fijo comparable de extinguirse su contrato por otra causa objetiva, siendo en este caso evidente la igualdad en los términos de comparación respecto de la trabajadora a la que ha venido sustituyendo».

La controversia surge porque la doctrina jurisprudencial del TJUE ha cambiado en poco tiempo. Concretamente nos estamos refiriendo al asunto Caso Cristian Pujante Rivera contra Gestora Clubs Dir, S.L. y Fondo de Garantía Salarial (C-422/14), sentencia de 11 de noviembre de 2015 en que resuelve una cuestión prejudicial planteada por el Juzgado de lo Social n.$^{\circ} 33$ de Barcelona. Aquí el Tribunal sostenía que es compatible con la normativa comunitaria la diferencia de trato entre trabajadores indefinidos y temporales ${ }^{5}$ «El artículo 1, apartado 1, párrafo primero, letra a), de la Directiva 98/59/CE del Consejo, de 20 de julio de 1998, relativa a la aproximación de las legislaciones de los Estados miembros que se refieren a los despidos colectivos, debe interpretarse en el sentido de que los trabajadores con un contrato celebrado por una duración o para una tarea determinadas deben considerarse incluidos entre los trabajadores «habitualmente» empleados, en el sentido de este precepto, en el centro de trabajo de que se trate». Si bien se indica que «Asi, por una parte, ese legislador ha considerado que las personas con contratos de trabajo celebrados por una duración o para una tarea determinadas y cuyos contratos finalizan regularmente por la llegada del término resolutorio o por la conclusión de la tarea encargada no necesitan ser protegidos de la misma manera que los trabajadores por tiempo indefinido. De conformidad con el artículo 1, apartado 2, letra a), de la Directiva 98/59 (LCE), el primer grupo de personas puede no obstante disfrutar de la misma protección que se concede a los trabajadores contratados por tiempo indefinido si se encuentran en una situación análoga, esto es, si se pone fin a la relación laboral antes del término fijado en el contrato o antes de que haya concluido la tarea para la que fueron contratados» ${ }^{6}$.

5 «Distinto contrato ¿misma indemnización?» R. VÁZQUEZ RuIZ, en http://www.elderecho.com/22/09/2016.

6 Vid. Párrafo 39 de la sentencia TJUE de 11 de noviembre de 2015. 
Son muchos los interrogantes que esta sentencia arroja y que debe pulirse en sucesivos pronunciamientos de nuestra doctrina judicial a fin de que pueda entenderse sin lugar a dudas que una finalización de un contrato interino pueda constituir una causa objetiva, en los mismos términos que el despido de un contrato de un trabajador indefinido cuando la causa del despido no sea la reincorporación del trabajador sustituido sino por razones económicas o productivas ${ }^{7}$. En todo caso, coincidimos con el comentario de Cruz Villalón ${ }^{8}$ en el sentido de que con esta sentencia se ha desviado la atención de lo que realmente es importante en el mercado laboral. Concretamente hacer una diferenciación entre contratación temporal justificada y la abusiva, con una aceptación de la primera y penalización de la segunda y, por supuesto, la reestructuración de la Administración Pública que rompan con el abuso de las contrataciones temporales y especialmente la interinidad. De hecho, debe ponerse de relieve que el propio Juzgado de lo social del que trae su causa la sentencia que comentamos ya indicó que la contratación había sido abusiva, reconociendo que los contratos se celebraron en fraude de ley y que su relación laboral debia de haberse considerado indefinida.

\section{2. ¿DESIGUALDAD DE TRABAJADORES POR INDEMNIZACIÓN DIFERENTE DEPENDIENDO DE LA TEMPORALIDAD DEL CONTRATO? LA RECEPCIÓN DE LA JURISPRUDENCIA DEL TJUE POR LOS ÓRGANOS JUDICIALES}

En este apartado nos vamos a detener en dos aspectos de interés sobre la igualdad en relación a los trabajadores temporales y fijos y en relación a los trabajadores interinos y el resto de los trabajadores utilizando como parámetro el principio de igualdad a la luz del Convenio Marco incluido en la Directiva 1999/70 CE, de 28 de junio.

\subsection{Aplicación por los Tribunales nacionales de la jurisprudencia comunitaria en relación a los trabajadores interinos}

En la sentencia de 14 de septiembre de 2015 el TJUE responde básicamente a tres cuestiones planteadas de la manera que sigue:

7 Vid., «Los interinos tienen derecho a indemnización por fin de contrato, pero ¿qué cuantía?», Eduardo RoJo TORRECILlA, acceso el 23 de septiembre de 2016, http://www. eduardorojotorrecilla.es

8 Jesús CRUZ VillaLÓN, 27 de septiembre de 2016, http://jesuscruzvillalon.blogspot. com.es/ 
a) Ámbito de aplicación de la cláusula 4, apartado 1, del Convenio Marco ¿Se incluye entre las condiciones de trabajo el derecho a la indemnización por finalización de la relación laboral?

Esta cláusula establece en su apartado primero que «Por lo que respecta a las condiciones de trabajo, no podrá tratarse a los trabajadores con un contrato de duración determinada de una manera menos favorable que a los trabajadores fijos comparables por el mero hecho de tener un contrato de duración determinada, a menos que se justifique un trato diferente por razones objetivas.»

La misma inspira la redacción del artículo $15.6 \mathrm{ET}$ al señalar que « $\underline{\operatorname{los}}$ trabajadores con contratos temporales y de duración determinada tienen los mismos derechos que los trabajadores con contratos de duración indefinida». E incluso, «cuando un determinado derecho o condición de trabajo esté atribuido en las disposiciones legales o reglamentarias y en los convenios colectivos en función de una previa antigüedad del trabajador, ésta deberá computarse según los mismos criterios para todos los trabajadores, cualquiera que sea su modalidad de contratación ${ }^{9}$. Ello es aplicable a todos los trabajadores, también a los trabajadores en la Administración Pública, como se reconoce en la STJ Cantabria de 8 de junio de $2005^{10}$. Conviene resaltar que en interpretación de esta cláusula, la sentencia TJUE de 13 de septiembre de 2007 (asunto C-307/05), que resuelve una petición de decisión

${ }^{9}$ En aplicación de esta normativa, destaca la sentencia del TSJ Cantabria de 20 de enero de 2005 «en particular, en lo que respecta a la igualdad de trato de los trabajadores temporales -siempre dentro del marco de la norma estatal y la autonomía colectiva apuntadas- se ha declarado con reiteración que los convenios colectivos no pueden excluir de su ámbito de aplicación a los trabajadores temporales ni establecer para éstos condiciones diferentes de signo peyorativo que no pueden justificarse por la temporalidad del vínculo. Especialmente, con relación al distinto trato retributivo derivado de la diversa modalidad de contratación se ha dicho que destruye la proporcionalidad que es uno de los aspectos de la igualdad, haciendo de peor condición artificiosamente a quienes ya lo son por la eventualidad del empleo, enmascarando una infravaloración de su trabajo. No se aprecia en este caso más factor diferencial que el meramente temporal, la duración, insuficiente como fundamento de la menor retribución (SSTC 52/1987, 136/1987, 177/1993, SSTS 13 y 22 mayo, 27 noviembre 1991, 23 de julio de 1999, 6 de julio de 2000, 3 de octubre de 2000), vid., PALOMINO SAURINO, P., «¿Es discriminatorio para el trabajador no reconocerle los trienios correspondientes al tiempo que ha trabajado como personal estatutario temporal?». Revista Doctrinal Aranzadi Social n. ${ }^{\circ}$ 15/2007.

10 «En el ámbito de las Administraciones Públicas, la aplicación del principio de igualdad constitucional resulta mucho más rígida que en el ámbito de las relaciones entre particulares, pues en aquéllas rige, de forma estricta y rígida, y así puede verse cómo la sentencia del TC 161/1991 afirmó que "cuando el empresario es la administración pública, ésta no se rige por el principio de autonomía de la voluntad sino que debe actuar con sometimiento pleno a la Ley y al derecho (artículo 130.1 CE), con interdicción de la arbitrariedad (art. 9.3)"”.. 
prejudicial planteada por un juzgado de San Sebastián en el marco de un litigio entre una empleada estatutaria temporal y el Servicio Vasco de Salud sobre el pago de un complemento salarial, concretamente los trienios ${ }^{11}$, señalaba que «(...) habida cuenta de la importancia de los principios de igualdad de trato y de no discriminación, que forman parte de los principios generales del Derecho comunitario, a las disposiciones previstas por la Directiva 1999/70 y el Acuerdo marco a efectos de garantizar que los trabajadores con un contrato de duración determinada disfruten de las mismas ventajas que los trabajadores por tiempo indefinido comparables, salvo que esté justificado un trato diferenciado por razones objetivas, debe reconocérseles un alcance general, dado que constituyen normas de Derecho social comunitario de especial importancia de las que debe disfrutar todo trabajador, al ser disposiciones protectoras mínimas». Indicando seguidamente que el principio de no discriminación como principio básico del derecho social comunitario no puede interpretarse de forma restrictiva. Es decir, el Tribunal aquí hace un pronunciamiento favorable para que a los empleados públicos se le aplique esta Directiva igual que al resto de los trabajadores ${ }^{12}$. Será el Estatuto Básico del Empleado Público (Real Decreto Legislativo 5/2015, de 30 de octubre) el que establezca el derecho de los empleados públicos temporales a recibir los trienios (art. 25) ${ }^{13}$, aunque ya se había previsto en la anterior Ley del 2007. La sentencia de 22 de diciembre de 2010 Caso Gavieiro Gavieiro y

${ }^{11}$ En el asunto que nos ocupa la demandante, una trabajadora estatutaria fija del Servicio Vasco de Salud, había trabajado antes de obtener esta categoría durante más de doce años como auxiliar administrativa en diversos hospitales, formando parte durante ese periodo del «personal estatutario temporal». Al no serle reconocido su derecho a obtener el pago de los trienios vencidos durante el año anterior a su nombramiento, decide acudir al Juzgado de lo Social, alegando que la negativa a concederle con carácter retroactivo los efectos económicos resultantes del reconocimiento de la antigüedad en el servicio, constituye una discriminación al «personal estatutario temporal» con relación al «personal fijo de plantilla». vid., PAlomino SAURINo, P., ¿Es discriminatorio...?, op. cit.

${ }_{12}$ Indicando así que se aplica «(...) a los contratos y relaciones laborales de duración determinada celebrados por los órganos de la Administración y demás entidades del sector público», añadiéndose que "La mera circunstancia de que un empleo sea calificado como «de plantilla» con arreglo al Derecho nacional y presente alguno de los elementos que caracterizan a la función pública del Estado miembro de que se trate carece de relevancia a este respecto, so pena de desvirtuar gravemente la eficacia de la Directiva 1999/70 y del Acuerdo marco, así como la aplicación uniforme de éstos en los Estados miembros, reservando a estos últimos la posibilidad de excluir a su arbitrio a determinadas categorías de personas del beneficio de la protección requerida por estos instrumentos comunitarios».

13 «1. Los funcionarios interinos percibirán las retribuciones básicas y las pagas extraordinarias correspondientes al Subgrupo o Grupo de adscripción, en el supuesto de que éste no tenga Subgrupo. Percibirán asimismo las retribuciones complementarias a que se refieren los apartados b), c) y d) del artículo 24 y las correspondientes a la categoría de entrada en el cuerpo o escala en el que se le nombre. 
en un asunto similar al anterior señalaba que «la mera circunstancia de que una disposición nacional como el art. 25 apartado 2 de la Ley 7/2007, de 12 de abril, del Estatuto Básico del Empleado Público no contenga ninguna referencia a la Directiva 1999/70 no excluye que dicha disposición pueda ser considerada una medida nacional de trasposición del Directiva al derecho interno» ${ }^{14}$.

Más recientemente la sentencia del TJUE de 9 de julio de 2015 (Caso Regojo Dans) y referido a la situación de los trabajadores eventuales, entiende que la normativa española incumple la Directiva cuando excluye sin justificación alguna por razones objetivas, al personal eventual del derecho a percibir los trienios concedidos a los funcionarios de carrera si ambas categorías de trabajadores se encuentran en situación comparable. En consecuencia, el complemento salarial de antigüedad es aplicable a todos los trabajadores dado que la naturaleza temporal o no de la relación laboral no es una causa objetiva de acuerdo con el Acuerdo Marco para considerarse justificada la diferenciación de trato.

En definitiva respecto a la primera cuestión se trata de dilucidar si se justifica el trato diferente de los trabajadores por el hecho de tener un contrato indefinido o de duración determinada. Esto es, ¿ello justifica un trato diferente por condiciones de trabajo? Aquí el Tribunal indica que el objetivo de este Acuerdo Marco incluido en la Directiva es favorecer la igualdad de trato de los trabajadores de duración determinada en relación a los trabajadores indefinidos en sus «condiciones de trabajo». Considera por condiciones de trabajo y, en consecuencia, la necesaria igualdad de todos los trabajadores, lo siguiente:

- El derecho a la percepción de los trienios que es un elemento retributivo al que tienen derecho los trabajadores con independencia de la duración de su contrato ${ }^{15}$. También aplicable a los «sexenios»

- Dentro de la igualdad en las condiciones de trabajo se incluye también el plazo de preaviso aplicable en caso de finalización de los contratos de duración determinada ${ }^{16}$.

2. Se reconocerán los trienios correspondientes a los servicios prestados antes de la entrada en vigor del presente Estatuto que tendrán efectos retributivos únicamente a partir de la entrada en vigor del mismo».

14 Fundamento tercero de la sentencia.

15 En este sentido se pronuncian las sentencias de 13 de septiembre de 2007 (TJCE 2007, 229), Del Cerro Alonso (C-307/05), apartado 47, y de 22 de diciembre de 2010 (TJCE 2010, 414), Gavieiro Gavieiro e Iglesias Torres, (C-444/09 y C-456/09), apartados 50 a 58.

16 Así la sentencia de 13 de marzo de 2014 (TJCE 2014, 101), Nierodzik, (C-38/13), apartados 27 y 29 . 
- En las condiciones de trabajo también se incluye el derecho a la indemnización pues el criterio decisivo es la determinación de si una medida está incluida en el concepto de empleo, o dicho en otras palabras, en la relación entre empleador y trabajador ${ }^{17}$. De esta forma y dando respuesta a la primera cuestión prejudicial el Tribunal sostiene que «debe interpretarse la cláusula 4 apartado 1 del Acuerdo Marco en el sentido de que el concepto de "condiciones de trabajo» incluye la indemnización que un empresario está obligado a abonar a un trabajador por razón de la finalización de su contrato de trabajo de duración determinada ${ }^{18}$.

b) ¿Existen razones objetivas para justificar un tratamiento diferenciado en relación a la indemnización, teniendo en cuenta el carácter temporal o no de la relación de trabajo?

Entiende el TJUE en la sentencia de 14 de septiembre de 2016 que «La cláusula 4 del Acuerdo marco sobre el trabajo de duración determinada, que figura en el anexo de la Directiva 1999/70, debe interpretarse en el sentido de que se opone a una normativa nacional, como la controvertida en el litigio principal, que deniega cualquier indemnización por finalización de contrato al trabajador con contrato de interinidad, mientras que permite la concesión de tal indemnización, en particular, a los trabajadores fijos comparables. El mero hecho de que este trabajador haya prestado sus servicios en virtud de un contrato de interinidad no puede constituir una razón objetiva que permita justificar la negativa a que dicho trabajador tenga derecho a la mencionada indemnización».

Esta afirmación que parece clara, sin embargo conlleva algunos interrogantes tales como si en virtud a esta cláusula, ¿cabe la equiparación en la indemnización a todos los trabajadores con independencia de que sean temporales o indefinidos en el umbral 20 o 33 días de indemnización por año de servicio? Además, el tema es mucho más complejo porque en los contratos temporales, si éstos se extinguen por causas legales sobrevenidas (antes de la finalización del contrato) las indemnizaciones se calculan en los mismos parámetros (20 días) y por ende no hay aquí disparidad alguna

17 De acuerdo con las sentencias de 12 de diciembre de 2013 (TJCE 2013, 448), Carratù, C-361/12, apartado 35, y de 13 de marzo de 2014 (TJCE 2014, 101), Nierodzik, C-38/13, EU:C:2014:152, apartado 25).

18 En el mismo sentido, vid., TJUE, sentencia de 13 marzo 2014; TJUE sentencia de 12 diciembre 2013; TJUE, sentencia de 18 octubre 2012; TJUE, sentencia de 8 septiembre 2011; TJUE, sentencia de 22 diciembre 2010; TJCE sentencia de 13 septiembre 2007. 
en el derecho a la indemnización teniendo en cuenta la temporalidad del contrato ${ }^{19}$.

\section{c) ¿Es discriminatoria la regulación del Estatuto de los Trabajadores? ${ }^{20}$}

Concretamente nos centramos en el artículo 49, apartado 1, letra c), del Estatuto de los Trabajadores. Dispone que a la finalización del contrato, excepto en los casos del contrato de interinidad y de los contratos formativos, el trabajador tendrá derecho a recibir una indemnización de cuantía equivalente a la parte proporcional de la cantidad que resultaría de abonar doce días de salario por cada año de servicio. Por su parte, el artículo 53, apartado 1, letra b), del mismo texto legal indica que la extinción del contrato por causas objetivas genera "[la puesta] a disposición del trabajador, simultáneamente a la entrega de la comunicación escrita, la indemnización de veinte días por año de servicio, prorrateándose por meses los períodos de tiempo inferiores a un año y con un máximo de doce mensualidades».

Dice el TJUE en la sentencia de 14 de septiembre de 2016 que a la recurrente debe aplicarse las mismas condiciones de trabajo pues al mantener su relación laboral durante tan largo periodo de tiempo (siete años consecutivos) permite considerar que la trabajadora tenia los mismos requisitos de formación y el mismo trabajo que la persona a la que reemplazó ${ }^{21}$. En este sentido entiende el Tribunal que «ni la naturaleza

${ }^{19}$ Una de las críticas de esta sentencia más reiterada es su falta de precisión técnica Vid., I. Beltrán de Heredia Ruiz, «Una mirada crítica a las relaciones laborales», Blog de Derecho del Trabajo y de la Seguridad Social, http://ignasibeltran.com/

${ }^{20}$ De acuerdo con el art. 15 apartado 1 ET el contrato de trabajo podrá concertarse por tiempo indefinido o por una duración determinada. Podrán celebrarse contratos de duración determinada en los siguientes supuestos:

«a) Cuando se contrate al trabajador para la realización de una obra o servicio determinados, con autonomía y sustantividad propia dentro de la actividad de la empresa y cuya ejecución, aunque limitada en el tiempo, sea en principio de duración incierta. [...]

b) Cuando las circunstancias del mercado, acumulación de tareas o exceso de pedidos así lo exigieran, aun tratándose de la actividad normal de la empresa. [...]

c) Cuando se trate de sustituir a trabajadores con derecho a reserva del puesto de trabajo, siempre que en el contrato de trabajo se especifique el nombre del sustituido y la causa de sustitución».

En virtud del artículo 15, apartado 3, del Estatuto de los Trabajadores, «se presumirán por tiempo indefinido los contratos temporales celebrados en fraude de ley».

${ }^{21}$ Párrafo 42 «En efecto, el propio hecho de que la mencionada recurrente ocupara durante siete años consecutivos el mismo puesto de una trabajadora en situación de dispensa de obligaciones laborales vinculada a su condición sindical no sólo permite concluir que la interesada cumplía los requisitos de formación para acceder al puesto de trabajo de que se trata, sino también que efectuaba el mismo trabajo que la persona a la 
temporal de la relación laboral ni la inexistencia de disposiciones en la normativa nacional relativas a la concesión de una indemnización por finalización de un contrato de trabajo de interinidad pueden constituir, por si solas, tales razones objetivas ${ }^{22}$ Concluye señalando que «El mero hecho de que este trabajador hava prestado sus servicios en virtud de un contrato de interinidad no puede constituir una razón objetiva que permita justificar la negativa a que dicho trabajador tenga derecho a la mencionada indemnización $»^{23}$.

En definitiva, el Tribunal hace una lectura del principio de igualdad de los trabajadores teniendo en cuenta el Acuerdo Marco anteriormente mencionado, aunque no es la única norma europea que se pronuncia sobre el principio de igualdad en el marco de las relaciones de trabajo. Traemos a colación el art. 21.1 de la Carta de Derechos Fundamentales de la Unión Europea (en adelante CDFUE $)^{24}$ al indicar que «...Se prohíbe toda discriminación, y en particular la ejercida por razón de sexo, raza, color, orígenes étnicos o sociales, características genéticas, lengua, religión o convicciones, opiniones políticas o de cualquier otro tipo, pertenencia a una minoría nacional, patrimonio, nacimiento, discapacidad, edad u orientación sexual...». A estos efectos no debe obviarse la articulación de la Carta en tres subsistemas. Por un lado el propiamente comunitario; por otro, el derecho internacional y la deriva del Convenio Europeo de Derechos Fundamentales y, finalmente, su aplicación de acuerdo con la interpretación que deben hacer los Estados de su derecho interno de conformidad con los Tratados Internacionales suscritos por los mismos (art. 10.2 CE) $)^{25}$.

No obstante, lo anterior contrasta con la anterior doctrina del Tribunal Constitucional elaborada en relación con el principio de igualdad en el ámbito laboral que ha manifestado que «(...) el funcionariado o personal interino presenta unas importantes peculiaridades con respecto al funcionariado de carrera que hacen objetivo y razonable un tratamiento diferenciado en materia retributiva entre una u otra categoría de personal al servicio de la Administración y ello tanto más en un tipo específico de concepto

$\overline{q u e ~ r e m p l a z o ́ ~ d e ~ f o r m a ~ p e r m a n e n t e ~ d u r a n t e ~ e s t e ~ l a r g o ~ p e r i o d o ~ d e ~ t i e m p o, ~ a p l i c a ́ n d o s e l e ~}$ también las mismas condiciones de trabajo. En consecuencia, procede considerar que la situación de trabajador con contrato de duración determinada de la recurrente en el litigio principal era comparable a la de un trabajador fijo».

22 Párrafo 50.

23 Párrafo 52.

24 Aprobada por Acuerdo de 7 de diciembre 2000.

25 Vid., Cámara Villar, G., «Los derechos fundamentales en el proceso histórico de construcción de la Unión Europea y su valor en el Tratado constitucional», ReDCE, n. ${ }^{\circ} 4$, 2005, pp. 9-42. 
retributivo esencialmente ligado a la propia carrera funcionarial como es el referido a los trienios» (ATC 112/2008, de 14 de abril) ${ }^{26}$.

\subsection{Aplicación por los Tribunales nacionales de la jurisprudencia comunitaria en el trato igualitario entre trabajadores temporales y fijos}

Otra sentencia de gran interés es también la de 14 de septiembre de 2016 del TJUE (n. $\left.{ }^{\circ} 110 / 2016\right)$. Se trata de una resolución que resuelve dos cuestiones prejudiciales planteadas por el Tribunal Superior de Justicia del País Vasco mediante autos de 9 de marzo del 2015 y 29 de abril de 2015. En el primer asunto la demandante obtuvo un total de trece prórrogas de su contrato como personal estatutario temporal eventual en la categoría de auxiliar administrativo sin motivación específica en relación a las prórrogas. En el segundo caso el demandante trabajó como arquitecto para el Ayunta miento de Vitoria-Gasteiz en diferentes categorías desde 1993 hasta 2012 que se puso fin a su relación de servicio con el Ayuntamiento.

Se pone en tela de juicio en ambos asuntos la utilización abusiva de la contratación temporal en el seno de la Administración Pública sin justificación razonable. Concretamente se trata de dilucidar si se está aplicando correctamente la Directiva 1999/70 en la normativa nacional y en la práctica judicial al no reconocerse al personal estatutario temporal eventual ni a los funcionarios interinos el derecho al mantenimiento de su relación laboral. La pregunta principal es «1) La cláusula $5^{27}$, apartado 1, del [Acuerdo Marco] ¿debe ser interpretada en el sentido de que se opone a una legislación nacional que, en los supuestos de abusos como consecuencia de la utilización de contratos de trabajo de duración determinada, no reconoce con carácter general, en el caso del personal estatutario temporal eventual [(asunto

26 Vid., C. Romero ReY, «El efecto directo de la Directiva sobre el trabajo de duración determinada y su incidencia en el personal interino de las Administraciones públicas españolas». Revista Aranzadi Unión Europea (12/2010).

27 «1. A efectos de prevenir los abusos como consecuencia de la utilización sucesiva de contratos o relaciones laborales de duración determinada los Estados miembros, previa consulta con los interlocutores sociales y conforme a la legislación, los acuerdos colectivos y las prácticas nacionales, y/o los interlocutores sociales, cuando no existan medidas legales equivalentes para prevenir los abusos, introducirán de forma que se tengan en cuenta las necesidades de los distintos sectores y/o categorías de trabajadores, una o varias de las siguientes medidas:

a) razones objetivas que justifiquen la renovación de tales contratos o relaciones laborales;

b) la duración máxima total de los sucesivos contratos de trabajo o relaciones laborales de duración determinada;

c) el número de renovaciones de tales contratos o relaciones laborales». 
C-184/15) y los funcionarios interinos (asunto C-197/15)] y a diferencia de lo que ocurre en idéntica situación para los contratados laborales por la Administración, el derecho al mantenimiento del vínculo como indefinidos no fijos, es decir, con derecho a ocupar la plaza desempeñada temporalmente hasta su cobertura en forma reglamentaría o su amortización por los procedimientos legalmente establecidos?».

Como argumentación de peso el Tribunal sostiene que es indispensable que en el derecho interno se arbitre medidas que garanticen la protección de los trabajadores cuando se produce una utilización abusiva de la temporalidad. Así pues entiende que en sí misma cabe que la normativa nacional prohíba de forma absoluta en el sector público la transformación en un contrato de trabajo por tiempo indefinido una sucesión de contratos de duración determinada. No obstante, para que ello sea conforme con el Acuerdo Marco es imprescindible que en el Ordenamiento Jurídico del Estado miembro se establezca otra medida para evitar y, en su caso, sancionar el abuso en este tipo de contrataciones. Desde este punto de vista y, teniendo en cuenta que existe ya una medida eficaz contra este abuso en lo que respecta los empleados públicos sujetos al derecho laboral por la consagración por la jurisprudencia del TS del concepto de trabajador indefinido no fijo, cabría la asimilación para el personal que presta los servicios a las administraciones públicas en régimen de derecho administrativo. De esta forma no habría infracción de la cláusula cinco del Acuerdo Marco.

Como ya hemos señalado más arriba, en aplicación de la jurisprudencia del TJUE, la Sala de lo Social del TSJ del País Vasco dicta sentencia el 18 de octubre de 2016 haciéndose eco de lo argumentado por el Tribunal europeo. En el caso que nos ocupa, a diferencia del de la sentencia del TSJ Madrid, no se está poniendo en tela de juicio la igualdad de trato desde el punto de vista de la indemnización entre trabajadores interinos (que, de acuerdo con nuestra legislación, no tienen derecho a dicha indemnización) y trabajadores temporales y fijos. Aquí la dicotomía se encuentra en la igualación de los temporales y fijos en su indemnización cuando exista una causa objetiva para el despido. Así, dado que en el ET se distingue entre uno y otro con un derecho de indemnización que varía de doce a veinte días por año de servicio, se trataría de analizar si esta legislación es inconstitucional por afectar al principio de igualdad tal como ha sido interpretado por el TJUE y, en consecuencia, se debe establecer para todos los trabajadores (con independencia de su temporalidad) la misma indemnización.

Piénsese que en el caso de la sentencia del TSJ País Vasco de 18 de octubre de 2016 al elevar la indemnización a 20 días para los trabajadores temporales al acabar su contrato, su repercusión es muy alta dada la elevada tasa de temporalidad que presenta nuestro mercado laboral. En los nueve primeros meses de este año se ha formado 14.668 millones de contratos, de los que $91,35 \%$ han sido temporales (13.699 millones). Solo un $8.65 \%$ fueron indefinidos según 
datos del Ministerio de Empleo y Seguridad Social ${ }^{28}$. En el supuesto de hecho de la sentencia se considera ajustada a derecho la terminación del contrato por tiempo determinado suscrito entre los trabajadores (de limpieza) y la empresa. No obstante y, como indica en el Fundamento Jurídico sexto, durante el procedimiento se tiene noticia de la sentencia del TJUE lo que obliga a este Tribunal a plantearse si el supuesto de hecho queda subsumido en el fallo de este tribunal. Considera que se trata de dilucidar si la diferente indemnización de los trabajadores temporales y fijos es conforme al derecho comunitario (Directiva 1999/70/CE, de 28 de junio) a pesar de que la normativa española, como es sabido, hace un trato diferenciado. Al tratarse de un contrato es obra o servicio determinado del art. 15.1 a) del ET, parece que claro que entra en la calificación de contrato de duración determinada al que se refiere la Cláusula 3.1 del Acuerdo Marco incluido en la Directiva que comentamos ${ }^{29}$.

Como parte fundamental de la sentencia queremos resaltar el FJ octavo cuando indica que «Es cierto, que el tipo de contrato que ahora analizamos y a diferencia del que trae causa la sentencia del TSJ de Madrid y por ende la del TJUE, tiene reconocida legalmente una indemnización al momento de extinguirse-art. 49.l.c) y disposición transitoria décimo tercera del ET...-. Pero con todo, persiste una distinción en el trato a dispensar al actor, ya que aun haciendo caso omiso de la última norma citada, la diferencia indemnizatoria seguiría siendo sustancial -12 días frente a 20 por año de servicio-, $y$, reiteramos, sin una causa que lo justifique y como no sea la temporalidad contractual»

Por lo que termina concluyendo la citada sentencia en que «no existe una justificación objetiva y razonable para que el actor no perciba la misma indemnización que la establecida para un trabajador fijo que fuera despedido por causas objetivas-productivas, ya que la situación extintiva es idéntica - parágrafos 45-47 de la sentencia»

\section{LA RECEPCIÓN DE LA JURISPRUDENCIA DEL TJUE POR EL TRIBUNAL CONSTITUCIONAL}

El TC, en STC de 14 de abril de 2016 (71/2016) da respuesta a la cuestión de inconstitucionalidad n. ${ }^{\circ}$ 289-2014 promovida por la Sala de lo Social del

28 Vid., ABC 30 de octubre de 2016.

${ }^{29}$ Donde se establece que se entenderá por: «...trabajador con contrato de duración determinada: el trabajador con un contrato de trabajo o una relación laboral concertados directamente entre un empresario y un trabajador, en los que el final del contrato de trabajo o de la relación laboral viene determinado por condiciones objetivas tales como una fecha concreta, la realización de una obra o servicio determinado o la producción de un hecho o acontecimiento determinado...». 
Tribunal Superior de Justicia de Canarias contra la disposición quincuagésima séptima de la Ley 10/2002, de 29 de diciembre de Presupuesto Generales de la Comunidad Autónoma de Canarias por vulneración del art. 14 en la interpretación que debe darse de acuerdo con la cláusula cuatro del Acuerdo Marco de la Directiva citada. Se alega, entre otros argumentos, que la norma cuestionada establece condiciones de trabajo diferentes y más perjudiciales al personal laboral indefinido y personal temporal frente al personal laboral fijo. El argumento por parte del Gobierno de Canarias gira en torno a la desestimación por entender que la naturaleza temporal o fija del vínculo laboral con la administración es suficiente para justificar la diferencia de trato ${ }^{30}$. En este caso la disposición no afecta a los interinos sino que limita su objeto al personal laboral indefinido y temporal. Así pues, es la temporalidad del contrato de trabajo (trabajadores fijos por un lado y trabajadores indefinido y temporales por otro) lo que determina la aplicación de la reducción dela jornada de un $20 \%$ o no.

Entiende el TC (haciéndose eco de la jurisprudencia comunitaria) que toda diferencia de trato debe estar basada en razones objetivas y, en el caso que nos ocupa, la diferenciación únicamente marcada en la duración de la relación laboral es injustificable por razones objetivas $\mathrm{y}$, en consecuencia, vulnera el art. 14 de la CE. Se apoya el Tribunal en la Directiva 1999\70\CE y dice textualmente el TC «Conviene señalar que el Tribunal de Justicia de la Unión Europea, cuando se ha pronunciado sobre la interpretación del principio de no discriminación contenido en la referida cláusula 4.1 de la Directiva 1999/70/CE ha establecido una doctrina muy similar a la que ha llegado este Tribunal en relación con las diferencias de trato entre trabajadores fijos y temporales. Esta doctrina se ha establecido, entre otras, en Sentencias que han sido dictadas con ocasión de cuestiones prejudiciales planteadas por jueces españoles sobre complementos retributivos que la normativa interna no reconocía a los funcionarios interinos». Continúa señalando que para apreciar si los trabajadores tienen idéntico trabajo o similar hay que analizar un conjunto de factores como la naturaleza del trabajo, las condiciones de formación y las condiciones laborales. La mera naturaleza temporal del personal al servicio de la Administración Pública no es razón

${ }^{30}$ «La disposición adicional quincuagésima séptima de la Ley de presupuestos de la Comunidad Autónoma de Canarias ha previsto con carácter coyuntural durante el ejercicio 2013, por razones de contención del gasto público, una reducción de la jornada de trabajo del personal funcionario interino y del personal laboral temporal e indefinido de un 20 por 100. Esta medida no se aplica a los empleados públicos vinculados a la prestación de servicios públicos esenciales, como justicia, sanidad y educación. Para los trabajadores con jornada de trabajo a tiempo parcial inferior a 25 horas semanales la reducción es del 10 por $100 »$. 
objetiva para la diferenciación por lo que incumpliría la cláusula cuatro del Acuerdo $\mathrm{Marco}^{31}$. Así pues parece claro que la disposición impugnada establece una diferencia de trato entre trabajadores temporales (en los que se incluye el personal laboral indefinido) y fijos. Si bien ello no basta para infringir el art. 14 y la cláusula 4 del Acuerdo Marco. Es necesario que esta diferenciación no esté basada en condiciones objetivas de trabajo. En el caso que nos ocupa la diferencia de trato no viene determinada por razones objetivas sino simplemente por el hecho de que el personal no tiene una relación de empleo fija con la Administración.

Destacamos también la STC 232/2015 de 5 de noviembre en cuyo fundamento jurídico sexto se alega al principio de primacía del derecho de la Unión lo que obliga a aplicar la cláusula 4.1 de la Directiva 1999/70/CE invocada por el recurrente tal y como había sido interpretada por el Tribunal de Justicia de la Unión Europea para casos semejantes (Sentencias del Cerro Alonso de 13 de septiembre de 2007 y Gavieiro Gavieiro e Iglesias Torres de 22 de diciembre de 2010, antes citadas). Se trataba del caso de la no concesión por un profesorado no universitario (funcionario interino) de determinadas retribuciones, concretamente por la denegación de reconocimiento a profesor interino del derecho a percibir los complementos específicos de formación o «sexenios». Hay que aclarar que ya existía jurisprudencia favorable al reconocimiento de esos sexenios a los funcionarios interinos ${ }^{32}$. Precisamente porque era una cuestión ya resuelta por el TJUE al resolver en una resolución anterior una cuestión prejudicial prácticamente idéntica, entiende el TC que la falta de aplicación de la Directiva citada sin motivación alguna supone la admisión del amparo dado que «(i) infringió el citado principio de primacía; (ii) incurrió, por ello, en una "selección irrazonable y arbitraria de una norma aplicada al proceso"; (iii) y, consiguientemente, vulneró, de este modo, el derecho a la tutela judicial efectiva del recurrente (art. 24.1 $C E)$ en los términos ya señalados por la jurisprudencia de este Tribunal

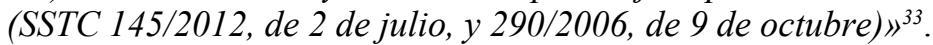

De esta forma y aunque efectivamente para acceder a un empleo fijo al servicio de la Administración es necesario pasar por un proceso selectivo que

${ }^{31}$ Sentencia Gavieiro Gavieiro e Iglesias Torres, C444/09 y C456/09, apartado 56, y Autos Montoya Medina, C273/10, apartado 42, y Lorenzo Martínez, C556/11, apartado 49.

32 Singularmente, Sentencia de la Sala 3. a del Tribunal Supremo de 22 de octubre de 2012, dictada en el recurso de casación en interés de la ley n. ${ }^{\circ} 5303 / 2011$, y Auto del Tribunal de Justicia de la Unión Europea de 9 de febrero de 2012, asunto C-556/11, caso Lorenzo Martínez, ambas resoluciones favorables a la equiparación de los profesores funcionarios interinos con los profesores funcionarios de carrera a estos concretos efectos de reconocimiento del derecho a percibir los llamados «sexenios».

33 Fundamento Jurídico sexto. 
acredite el mérito y la capacidad y que estos procesos selectivos son diferentes de los que deben superar quiénes tengan un vínculo temporal con la Administración, ello no justifica la diferencia de trato por sí misma conside$\mathrm{rada}^{34}$. Aquí podríamos plantearnos flagrantes incumplimientos a esta normativa en el ámbito universitario cuando no se retribuyen complementos docentes como quinquenios o sexenios dependiendo de la naturaleza funcionarial o contractual de la relación de profesor universitario con su Universidad (son varias las universidades españolas que reconocen dichos méritos docentes al profesorado laboral pero no lo retribuyen).

\section{HACIA LA CONSOLIDACION DEL TJUE COMO ACTOR DE CONSTITUCIONALIDAD}

No nos cabe duda de la importante función que está haciendo el TJUE en aras a homogeneizar la interpretación de los derechos fundamentales en la Unión Europea. La recepción de esta jurisprudencia por parte de nuestros tribunales ordinarios y del Tribunal Constitucional en asuntos de gran calado da buena fe de ello ${ }^{35}$.

Incluso el Tribunal de Justicia (Gran Sala), en su sentencia de 15 de abril de 2008 (asunto C-268/06), que resuelve la cuestión prejudicial

34 «La menor dificultad que tiene los procesos selectivos que superan quienes se incorporan con carácter temporal a la Administración pública respecto de los que tienen que superar aquellos que se integran como personal fijo no justifica que respecto de estos trabajadores se adopten medidas que no estén justificadas en datos objetivos relacionados con la prestación de trabajo que tienen que desempeñar o que sean consustanciales a la naturaleza temporal de su relación de empleo.», Vid., STC 71/2016 FJ 5.

35 Vid., Marc CARrillo, «Una institución de referencia», El País, 7 de octubre de 2016, el autor pone ejemplos de sentencias relevantes como la sentencia de 2013 en relación a que las normas hipotecarias españolas en los casos de desahucios de viviendas por impago del préstamos eran abusivas y no respetaban la directiva comunitaria sobre protección de consumidores (En el asunto C-415/11, Caso Mohamed Aziz contra Caixa d'Estalvis de Catalunya, Tarragona i Manresa (Catalunyacaixa) Sentencia de 14 de marzo de 2014 que señala textualmente «La Directiva 93/13/CEE del Consejo, de 5 de abril de 1993, sobre las cláusulas abusivas en los contratos celebrados con consumidores, debe interpretarse en el sentido de que se opone a una normativa de un Estado miembro, como la controvertida en el litigio principal, que, al mismo tiempo que no prevé, en el marco del procedimiento de ejecución hipotecaria, la posibilidad de formular motivos de oposición basados en el carácter abusivo de una cláusula contractual que constituye el fundamento del título ejecutivo, no permite que el juez que conozca del proceso declarativo, competente para apreciar el carácter abusivo de esa cláusula, adopte medidas cautelares, entre ellas, en particular, la suspensión del procedimiento de ejecución hipotecaria, cuando acordar tales medidas sea necesario para garantizar la plena eficacia de su decisión final». 
planteada por la Labour Court de Irlanda, indica que siempre que las disposiciones de una Directiva resulten ser, desde el punto de vista de su contenido, incondicionales y suficientemente precisas, los particulares podrán invocarlas frente al Estado, particularmente en su condición de empleador. Ha afirmado que la cláusula cuarta, apartado 1, de la Directiva, que antes hemos transcrito, tiene un contenido suficientemente preciso para que pueda ser invocada por un justiciable y aplicada por el juez. Concretamente señala en su fallo (2) que "La cláusula 4, apartado 1, del Acuerdo marco sobre el trabajo de duración determinada, celebrado el 18 de marzo de 1999, que figura como anexo de la Directiva 1999/70, es incondicional y lo suficientemente precisa para que un particular pueda invocarla ante un tribunal nacional» ${ }^{36}$.

Tal como se ha podido apreciar por los fallos jurisprudenciales que hemos indicado en los apartados anteriores se está produciendo una suerte de permeabilidad de la interpretación que del derecho comunitario hace el TJUE en nuestra jurisprudencia. Aunque como es sabido, no siempre ha sido así. Los padres fundadores de la integración europea no incluyeron en los Tratados de París y Roma una Carta de Derechos. Ni en el Tratado de Roma ni en el de París había nada que pudiese hacer temer que el ejercicio de las competencias atribuidas a las Comunidades europeas fuese una amenaza para los derechos garantizados por las Constituciones de los Estados miembros. Ni nadie, en aquel momento, podía tener duda alguna de que si ese improbable riesgo llegara a ser realidad, habrían de ser los Estados mismos los encargados de asegurar la protección de sus propios ciudadanos ${ }^{37}$.

En ausencia de dicha declaración de derechos, el Tribunal de Justicia de las Comunidades Europeas se había atribuido para sí la tarea de controlar las normas comunitarias desde el punto de vista de unos derechos que, debido al

${ }^{36}$ Continúa en su fallo tercero que «Los artículos 10 CE y 249 CE, párrafo tercero, y la Directiva 1999/70 deben interpretarse en el sentido de que una autoridad de un Estado miembro que actúe como empleador público no está autorizada a adoptar medidas, contrarias al objetivo perseguido por dicha Directiva y el Acuerdo marco sobre el trabajo de duración determinada respecto a la prevención de la utilización abusiva de contratos de duración determinada, que consisten en renovar tales contratos por una duración anormalmente larga en el periodo comprendido entre la fecha en que expira el plazo de adaptación a dicha Directiva y la de entrada en vigor de la Ley mediante la que se lleva a cabo dicha adaptación».

37 Así pues, los Tratados europeos no incluyeron un catálogo escrito de estos derechos; se limitaban a hacer referencia al Convenio Europeo para la Protección de los Derechos Humanos y de las Libertades Fundamentales. Asimismo, los Tratados hacían referencia a los derechos fundamentales tal y como resultan de las tradiciones constitucionales comunes de los Estados miembros, como principios generales del Derecho de la Unión. 
silencio de los Tratados, el propio Tribunal, tenía que ir descubriendo ${ }^{38}$. En un repertorio de derechos que no aparecían declarados, sino simplemente latentes en un conjunto de normas y tradiciones de límites imprecisos ${ }^{39}$. Ello contrasta con la situación actual en la que el Tribunal de Justicia de la Unión Europea está contribuyendo notablemente con su jurisprudencia al desarrollo y el respeto de los derechos fundamentales. Desde hace algunos años se ha venido observando, en los ámbitos de decisión de la Unión Europea, una creciente preocupación por la consecución de un sólido marco político en la protección de los derechos de los ciudadanos.

Con la adopción del Tratado de Lisboa la situación ha dado un cambio considerable, puesto que, desde entonces, la Unión cuenta con una Carta de los Derechos Fundamentales (en adelante CDFUE) jurídicamente vinculante desde diciembre de 2009 con el mismo valor jurídico que los Tratados, de conformidad con el artículo 6 del TUE ${ }^{40}$. Ello implica que la integración europea refuerza el estándar que tienen los derechos constitucionalmente reconocidos ${ }^{41}$.Así al reconocimiento de derechos en la CDFUE se le

${ }^{38}$ F. Rubio Llorente, «Una carta de dudosa utilidad», en AA.VV. La protección de los Derechos Fundamentales en la Unión Europea, ed por Francisco Javier MATIA PoRTILLA (dir.), (Madrid: 2002), 171-172.

${ }^{39}$ Lo que hace casi inevitable que el Tribunal que ha de aplicarlos se mueva, aun sin quererlo, entre la pasividad y el exceso de activismo Rubio Llorente, Una carta..., 180-181.

40 «1. La Unión reconoce los derechos, libertades y principios enunciados en la Carta de los Derechos Fundamentales de la Unión Europea de 7 de diciembre de 2000, tal como fue adaptada el 12 de diciembre de 2007 en Estrasburgo, la cual tendrá el mismo valor jurídico que los Tratados. Las disposiciones de la Carta no ampliarán en modo alguno las competencias de la Unión tal como se definen en los Tratados.

Los derechos, libertades y principios enunciados en la Carta se interpretarán con arreglo a las disposiciones generales del titulo VII de la Carta por las que se rige su interpretación y aplicación y teniendo debidamente en cuenta las explicaciones a que se hace referencia en la Carta, que indican las fuentes de dichas disposiciones.

2. La Unión se adherirá al Convenio Europeo para la Protección de los Derechos Humanos y de las Libertades Fundamentales. Esta adhesión no modificará las competencias de la Unión que se definen en los Tratados.

3. Los derechos fundamentales que garantiza el Convenio Europeo para la Protección de los Derechos Humanos y de las Libertades Fundamentales y los que son fruto de las tradiciones constitucionales comunes a los Estados miembros formarán parte del Derecho de la Unión como principios generales».

${ }^{41}$ De esta forma, las disposiciones de los Tratados y de la CDFUE se aúnan entre otras con las regulaciones del Convenio Europeo de Derechos Humanos y con las tradiciones constitucionales comunes de los Estados miembros de la Unión Europea, vid., Freixes Sanjuan, T., «Los derechos fundamentales en la Unión Europea, evolución y prospectiva: la construcción de un espacio jurídico europeo de los derechos fundamentales», ReDCE, n. ${ }^{\text { }}$ 4, 2005, pp. 43-86. 
acompaña de la revisión de garantías para su protección, a fin de asegurar que no se trate de un mero lavado de cara o una especie de marketing para vender mejor a los ciudadanos críticos o indiferentes una Unión Europea que quiere mantenerse a toda costa ${ }^{42}$.

Aún queda la Adhesión de la Unión al Convenio Europeo para la Protección de los Derechos Humanos y de las Libertades Fundamentales (CEDH). La UE como tal no es parte del CEDH, a diferencia de todos sus Estados miembros, que sí son parte del mismo y el artículo 6, apartado 2, del TUE obliga a la Unión a adherirse al CEDH. Dicha adhesión permitirá a los ciudadanos europeos, pero también a los ciudadanos de terceros países presentes en el territorio de la Unión, recurrir directamente ante este Tribunal, sobre la base de las disposiciones del CEDH, los actos jurídicos adoptados por la Unión, en las mismas condiciones que los actos jurídicos de sus Estados miembros ${ }^{43}$. Con independencia de la adhesión al CEDH lo que parece claro es que los ordenamientos jurídicos de los Estados de la Unión van cobrando unidad a través de la labor interpretativa del TJUE. Por lo que parece irreversible una progresiva unificación de los Derechos nacionales hacia las pautas interpretativas fijadas desde la $\mathrm{UE}^{44}$.

La ampliación de los horizontes del TJUE en materia de derechos fundamentales ha estado muy marcada, sobre todo, en aspectos como el derecho a la no discriminación. Así, mientras el TEDH ha fijado su línea jurisprudencial en materia de derechos en la fijación de estándar mínimos de tutela, la línea del TJUE va hacia otros derroteros por estar llamado por el art. 6 del TUE a hacer una operación interpretativa entre la tradición constitucional y el TUE a fin de extrapolar aquellos derechos que se encuadran en las

42 Vid., M.A. Alegre Martínez, «Derechos sociales en la Carta de los Derechos Fundamentales de la Unión Europea», en Escritos sobre derecho europeo de los derechos sociales, ed. Por AA.VV., (Valencia: 2004), 63-64; Vid., M.J. CARAZO LiéBANA, «La eficacia de la Carta de Derechos Fundamentales en la Proyectada constitución europea. En especial los derechos sociales», Foro Constitucional Iberoamericano, n. ${ }^{\circ}$ 8, 2004.

${ }_{43}$ Actualmente, la Unión Europea y el Consejo de Europa mantienen negociaciones sobre la adhesión de la Unión al Convenio. En julio de 2013, la Comisión pidió al Tribunal de Justicia que se pronunciara acerca de la compatibilidad del proyecto de acuerdo de adhesión con los Tratados. El 18 de diciembre de 2014, el Tribunal de Justicia consideró que el proyecto de acuerdo de adhesión de la UE al CEDH no era compatible con el Derecho de la UE (dictamen 2/13) vid., SALINAS DE FRÍAS, A., «La adhesión de la Unión Europea al Convenio Europeo de Derechos Humanos», 23 noviembre 2015 aquiescencia blog de derecho internacional de Carlos Espósito https://aquiescencia.net/2015/11/23/launion-europea-y-el-convenio-europeo-de-derechos-humanos-por-ana-salinas-de-frias/

${ }^{44}$ Vid., A. Lopez PINA, «Derecho europeo y principio constitucional de igualdad. El Tratado de la Unión ante la prueba de las tradiciones constitucionales», ReDCE , n. ${ }^{\circ} 4$, (2005): 123-136. 
finalidades fundamentales de los tratados ${ }^{45}$. Al final se trata de situar al Tribunal de Justicia en un sistema europeo de justicia constitucional, también llamado derecho constitucional común europeo ${ }^{46}$. Parece evidente que los Tribunales de justicia y los tribunales constitucionales europeos se mueven en un sistema europeo de justicia constitucional. Esta justicia constitucional europea debe concebirse en un plano de integración material y no sobre bases jerárquicas. La comparación es comunicación, y una comunicación óptima debe rehuir de tentativas de jerarquización y ello se produce cuando nadie tiene la última palabra. $\mathrm{O}$ mejor dicho, esa última palabra se percibe como argumento de autoridad que se aplica de forma natural, tal como hemos podido apreciar en la sentencia del TSJ del País Vasco de 18 de octubre de 2016. La comparación debe alimentarse del diálogo de culturas ${ }^{47}$. Podríamos hablar de un Estado constitucional cooperativo que va más allá de lo que se ha llamado dialogo de tribunales para constituir un auténtico sistema europeo de justicia constitucional produciéndose un desbordamiento del Estado constitucional de los límites del Estado nacional ${ }^{48}$. Ello es así porque el rol del juez ordinario ha cambiado. La ley debe interpretarse de acuerdo con las pautas fijadas por el TJUE dada la primacía que tiene la legislación comunitaria. El juez debe estar cauteloso en la aplicación del ordenamiento jurídico en una doble vertiente. Por un lado, que la norma se ajuste a la Constitución $\mathrm{y}$, si tiene dudas fundadas, plantear una cuestión de inconstitucionalidad. Pero también debe estar cauteloso en la aplicación de la normativa comunitaria y en el acervo jurisprudencial del TJUE a fin de plantear cuestiones prejudiciales si también le surge dudas fundadas o, en el caso de que haya jurisprudencia clara sobre la interpretación de la legislación comunitaria, aplicarla sin más aunque ello suponga, como los casos que hemos tratado en el presente estudio, la inaplicación de la legislación nacional.

Así pues se presenta un horizonte nuevo de control difuso de la constitucionalidad europea ${ }^{49}$. El ordenamiento de los derechos fundamentales de la Unión, coloca a los jueces en ese control de constitucionalidad difuso en que podrían dejar de aplicar el Derecho nacional en el caso de resultar contrario

${ }^{45}$ Vid., P. Ridola, «La justicia constitucional y el sistema europeo de protección de los derechos fundamentales», ReDCE, n. ${ }^{\circ} 18$ (2012): 217-248.

${ }^{46}$ Que se va formando como un ámbito de protección del individuo relativamente homogéneo, vid., R. URIARTE TORREALDAY, «Propiedad, libre empresa y trabajo: los derechos económicos en la constitución española y en el proyecto constitucional europeo», ReDCE, n. ${ }^{\circ}$ 4, (2005): 333-372.

47 Vid., Ridola, La justicia..., 248.

${ }_{48}$ Nos parece realmente sugestiva la interpretación que del constitucionalismo multinivel hace RADIOLA, La justicia... 246 y ss.

49 Vid., S. GAmBINO, «Identidad constitucional nacional, derechos fundamentales e integración europea», ReDCE, n. ${ }^{\circ} 18$ (2012): 55-94. 
con el Derecho de la Unión en el ámbito de los derechos fundamentales (como ha ocurrido en los supuestos comentados de la sentencia del TSJM de 8 de octubre del 2016 y la sentencia de 18 de octubre del 2016 del TSJ del País Vasco). Mediante la integración y la recepción de la jurisprudencia del TJUE y del Tribunal de Estrasburgo se ha creado lo que podríamos denominar «justicia europea de los derechos fundamentales» ${ }^{50}$. Efectivamente en el sistema de protección de los derechos fundamentales, los jueces ordinarios deben propiciar una tutela de los derechos constitucionales y de los derechos comunitarios en cuanto deben ser garantes de la aplicación no sólo del derecho interno (con la Constitución a la cabeza) sino también del derecho de la UE, convirtiéndose el juez estatal en aplicador básico de la CDFUE. Los jueces estatales deben tener en cuenta la interpretación realizada por su TC pero también por la del TJUE ya que la jurisprudencia de uno y otro son de obligado cumplimiento. En el caso del TC su supremacía viene demarcada por la supremacía de la Constitución respecto al resto del ordenamiento jurídico; pero también viene prevista en el art. 123.1 CE y del art. 5.1 LOPJ. En el caso del TJUE por el art. 93 de la CE y por la propia jurisprudencia del TC que le otorga una posición preeminente ${ }^{51}$.

En el espacio europeo conjugan tres bandas. La UE, el CEDH y las constituciones nacionales donde es fundamental articular unas pautas que permitan la pacífica convivencia de estos sistemas ${ }^{52}$. En el art. 52 apartado 3 de la CDFUE se dispone que «en la medida en que la presente Carta contenga derechos que corresponda a derechos garantizados por el Convenio Europeo para la Protección de los Derechos Humanos y de las Libertades Fundamentales, su sentido y alcance serán iguales a los que les confiere dicho Convenio». En el inciso final señala que «Esta disposición no obstará a que el Derecho de la Unión conceda una protección más extensa». Así se consagra que la Carta atribuye al CEDH un estándar mínimo de protección de la normativa europea, lo que no impide que la Carta dote a los derechos de una

50 Vid., FreiXes Sanjuan, Derechos Fundamentales..., 82.

${ }^{51}$ Destaca la STC 145/2012 que llega a sostener que si el juez ordinario no aplica una resolución del TJUE determinante está vulnerando el art. $24 \mathrm{CE}$ en cuanto al derecho a la tutela judicial efectiva en su vertiente de «derecho a recibir una sentencia motivada y fundada en Derecho»Vid., la brillante reflexión hecha sobre el tema por RODRIGUEZ-IzQuiERdo SERRANO, M., «Pluralidad de jurisdicciones y tutela de derechos: los, efectos de la integración europea sobre la relación entre el juez ordinario y el Tribunal Constitucional», Revista Española de Derecho Constitucional, n. ${ }^{\circ}$ 107, 2016, pp. 117-150.

52 Vid., A. Carmona Contreras, «El espacio europeo de los derechos fundamentales: de la Carta a las Constituciones nacionales», Revista Española de Derecho Constitucional, n. 107 (2016): 13-40; vid., N. PÉrEZ SolA, La defensa convencional de los derechos en España. ¿Es posible el diálogo entre Tribunales?, (Madrid: INAP, 2015). 
configuración más amplia ${ }^{53}$. Confirma lo anterior el art. 53 de la Carta «Ninguna de las disposiciones de la presente Carta podrá interpretarse como limitativa o lesiva de los derechos humanos y libertades fundamentales reconocidos, en su respectivo ámbito de aplicación, por el derecho de la UE, el derecho internacional y los convenios internacionales de los que son parte la Unión o todos los Estados miembros, y en particular el Convenio Europeo para la protección de los Derechos Humanos y de las Libertades Fundamentales así como por las constituciones de los Estados miembros».

Nos planteamos qué disposición debería prevalecer en caso de colisión entre las constituciones nacionales y la CDFUE. Podemos considerar que en aquellas parcelas en que la actuación estatal no está supeditada a la normativa europea, la constitución y la interpretación que de esta hace el TC se coloca en la cúspide del ordenamiento jurídico. Esto es, el estándar constitucional en la protección de los derechos queda inmune. Por el contrario, respecto a aquellas parcelas en que la normativa comunitaria sea aplicable en los Estados, el estándar lo fija la Carta por el principio de primacía del derecho comunitario ${ }^{54}$. Destacamos también la STC 232/2015, de 5 de noviembre que en su fundamento jurídico quinto entiende que «...sí corresponde a este Tribunal velar por el respeto del principio de primacía del derecho de la Unión cuando, como aquí ocurre según hemos avanzado ya, exista una interpretación auténtica efectuada por el propio Tribunal de Justicia de la Unión Europea. En estos casos, el desconocimiento y preterición de esa norma de derecho de la Unión, tal y como ha sido interpretada por el Tribunal de Justicia, puede suponer una «selección irrazonable y arbitraria de una norma aplicable al proceso», lo cual puede dar lugar a una vulneración del derecho a la tutela judicial efectiva (STC 145/2012, de 2 de julio [RTC 2012, 145], FFJJ 5 y 6 )》.

53 Vid., Carmona Contreras, El espacio europeo..., 27.

${ }^{54}$ Destaca la sentencia del TJUE de 26 de febrero de 2013 (C-399/11), asunto Melloni. En el supuesto de hecho de la sentencia nuestro Ordenamiento constitucional concedía un mayor grado de protección a los condenados en rebeldía en relación a la normativa europea (Decisión Marco del Consejo de 26 de febrero de 2009). Según nuestra doctrina constitucional en aplicación del derecho a la tutela judicial efectiva, no cabe la concesión de la extradición por parte de autoridades españolas a un país si este no garantiza la celebración de un nuevo juicio. El TC se topa con un dilema cual es el estándar de protección que debe aplicarse al caso. El TC plantea cuestión prejudicial ante el TJUE mediante Auto 86/2011, de 9 de junio. El TJUE en resolución de febrero de 2013 opta por el reconocimiento del canon europeo de protección de los derechos frente a las normas internas de los Estados aunque estas tengan carácter constitucional. Así la sentencia del TC 26/2014, de 13 de febrero, aplicando la doctrina emanada por el TJUE en la resolución de las cuestiones prejudiciales planteadas abandona su propia doctrina para acoger la propia jurisprudencia comunitaria, vid., CARMONA CONTRERAS, A., «El espacio europeo...», op. cit., pp. 36-37 
Al final son varias las cuestiones que nos podemos plantear ante el escenario del TJUE que se erige como un verdadero Tribunal de derechos fundamentales. ¿Cuál debe ser la posición de los Tribunales Constitucionales de los Estados miembros? ¿Cómo afecta el mandato europeo a jueces y tribunales respecto a la posición de supremacía que juega la jurisprudencia del TC en la interpretación de los derechos fundamentales y libertades públicas reconocidos en cada una de las Constituciones de los Estados miembros? ¿Se convierten los Tribunales constitucionales de los Estados miembros como «víctimas colaterales» de la CDFUE ${ }^{55}$ ? Obviamente no se nos escapa que estamos asistiendo a una «transformación del derecho constitucional» y de los actores encargados de velar por su correcta aplicación y por dar uniformidad a la interpretación de los derechos fundamentales. Esta transformación se está produciendo de manera rápida y está perfectamente permeabilizada por sus actores principales. Los Tribunales Constitucionales no están siendo reacios a esta transformación en los últimos años, ni se están aislando ni manteniendo indiferencia o lejanía hacia este proceso de europeización de los derechos fundamentales. Todo lo contrario, se están abriendo gradualmente al Derecho de la Unión y buena prueba de ello son las cuestiones prejudiciales que plantean al Tribunal de Justicia como es el caso del Auto del TC 86/2011, de 9 de junio que parte de la duda que se le plantea al TC de que la Decisión Marco 2002/584/JAI se ajuste a los derechos fundamentales garantizados por el ordenamiento comunitario, por el CEDH y por la Constitución española ${ }^{56}$. Destacamos el voto particular del Magistrado Pérez Tremps en el que, aun cuando discrepa del contenido o de las cuestiones principales de la cuestión prejudicial, no así del hecho de plantearla por considerar totalmente novedoso que el Tribunal Constitucional español se sume a ese proceso jurídico que se ha denominado el «diálogo de los tribunales»o «diálogo judicial europeo». Además, subraya que con la decisión de plantear esta cuestión prejudicial, el Tribunal se separa de su tradicional posición en la que negó explícita o implícitamente la posibilidad misma de acudir a este

55 Vid., X. Arzoz Santiesteban, La tutela de los derechos fundamentales de la Unión Europea por el Tribunal Constitucional, (Madrid: Instituto Nacional de la Administración Pública 2015), 18.

${ }^{56}$ Lo que se plantea es que si la condena en que trae su origen una Euroorden se ha producido sin que el condenado haya comparecido ante los tribunales que dictaron la condena ello podría haber vulnerado una garantía sustancial del proceso penal reconocida por el art. 24 de la Constitución «si esa posibilidad de ser condenado sin haber comparecido personalmente ante los Tribunales italianos, al estar amparada por la Decisión Marco, no supone una quiebra de las propias garantías procesales que el Derecho comunitario debe respetar por mandato directo del art. 6 TUE y 47 y 48 CDFUE interpretados a la luz del art. 6 del CEDH y de la jurisprudencia del Tribunal Europeo de Derechos Humanos, "canon privilegiado"». 
mecanismo prejudicial. Una de las cuestiones que suscita el caso en la sentencia TJUE (Gran Sala), 26 de febrero de 2013, asunto Stefano Melloni es la relativa al valor de la legislación europea derivada. Concluye que ésta ha de prevalecer en su ámbito de aplicación respecto de los derechos constitucionales de los Estados miembros cuando así se requiera para no comprometer la unidad y eficacia del derecho europeo ${ }^{57}$.

En definitiva, los Estados miembros de la Unión Europea ${ }^{58}$ comparten una cultura de los derechos fundamentales, tal y como se deriva de su pertenencia a la UE. Dicha cultura se ha consolidado a través de un parámetro común compuesto de diversos elementos: las previsiones normativas del Derecho comunitario, las tradiciones constitucionales comunes de los Estados miembros, la jurisprudencia del Tribunal de Justicia, el sometimiento de todos esos países al sistema de protección y garantía que ofrece el CEDH y la tarea que a su amparo lleva a cabo el Tribunal Europeo de Derechos Humano. Todo ello confiere al derecho constitucional europeo una compleja dimensión con varias dinámicas, que deben converger al ofrecimiento de un sistema de garantías para la protección de los derechos fundamentales en la que los operadores jurídicos permeabilicen el cambio tan radical que ello implica, sin que en ningún caso este proceso sea usado para una disminución de las garantías de los derechos.

TITLE: The Court of Justice of the European Union as an actor of constitutionality: About the interpretation of right to non-discrimination at work and its consequences

RESUMEN: La sentencia del Tribunal de Justicia de la Unión Europea de 14 de septiembre de 2016, abre la posibilidad de que los trabajadores temporales e interinos puedan reclamar una indemnización de 20 dias por año de servicio (o 33 si el despido es improcedente) al finalizar su contrato y/o ser despedidos. Ello es así aun cuando el Estatuto de los Trabajadores no prevea indemnización alguna para los trabajadores eventuales y una indemnización de 12 dias para los trabajadores

57 Desde Melloni (TJCE 2013, 54), ya no podrá confiarse en que el sistema nacional podrá mejorar los parámetros de protección acordados en la legislación secundaria -ésa era la interpretación del artículo 53 de la Carta que había realizado el Tribunal Constitucional español-y por ello será deseable lograr que sea la propia normativa europea, también la derivada, la que establezca el nivel de protección de derechos más alto Vid., L. Bachmaier Winter, «Más reflexiones sobre la sentencia Melloni: primacía, diálogo y protección de los derechos fundamentales en juicios in absentia en el derecho europeo» Revista Española de Derecho Europeo n. ${ }^{\circ}$ 56, (2015), BIB $2015 \backslash 16725$.

58 Tal como apunta el Magistrado Pérez Tremps en el voto particular del Auto TC $86 / 2011$. 
temporales. Se produce una suerte de control difuso de la legislación por parte de los tribunales ordinarios en relación a «sistema constitucional europeo». La ley nacional se interpreta de acuerdo con las pautas fijadas por el TJUE dada la primacía que tiene la legislación comunitaria, colocándose éste en el papel de actor de constitucionalidad tal como puede apreciarse en la praxis con recientes pronunciamiento jurisprudenciales en relación a la no discriminación de los trabajadores de duración determinada.

Palabras ClaVE: Constitución, Carta de Derechos Fundamentales de la Unión Europea, dialogo de tribunales, principio de no discriminación en el trabajo.

ABSTRACT: The sentence of the Court of Justice of the European Union of 14 September 2016, opens the possibility of temporary and interim workers to claim 20 days' compensation (or 33 if dismissal is unlawful) at the end of their contract and / or be fired. This is so, even if the Workers' Statute does not provide for any compensation for casual workers and a compensation of 12 days for temporary workers. It produces a kind of diffuse control of legislation by the ordinary courts in relation to "European constitutional system". The national law is interpreted according to the guidelines set by the CJEU given the primacy of Community law. This Court acquire the role of actor of constitutionality as can be seen in the praxis with recent jurisprudential pronouncement in relation to non-discrimination of fixed-term workers.

KEY WORDS: Constitution, Charter of Fundamental Rights of the European Union, dialogue of courts, principle of non-discrimination at work.

RECIBIDO: 08.02.2017

ACEPTADO: 17.05.2017 